OPEN ACCESS

Edited by:

Du Feng,

Guangzhou Medical University, China

Reviewed by:

Peter Schu,

University of Göttingen, Germany Matthew Seaman,

University of Cambridge,

United Kingdom

Sean Munro,

University of Cambridge,

United Kingdom

*Correspondence:

Da Jia

Jiada@scu.edu.cn

tThese authors have contributed equally to this work

Specialty section:

This article was submitted to Molecular Medicine

a section of the journal

Frontiers in Cell and Developmental

Biology

Received: 12 January 2020

Accepted: 28 February 2020

Published: 18 March 2020

Citation:

Tu Y, Zhao L, Billadeau DD and

Jia $D$ (2020) Endosome-to-TGN

Trafficking: Organelle-Vesicle

and Organelle-Organelle Interactions.

Front. Cell Dev. Biol. 8:163.

doi: 10.3389/fcell.2020.00163

\section{Endosome-to-TGN Trafficking: Organelle-Vesicle and Organelle-Organelle Interactions}

\author{
Yingfeng $\mathrm{Tu}^{1+}$, Lin Zhao ${ }^{1+}$, Daniel D. Billadeau ${ }^{2}$ and Da Jia ${ }^{1 *}$ \\ ${ }^{1}$ Key Laboratory of Birth Defects and Related Diseases of Women and Children, State Key Laboratory of Biotherapy, \\ Department of Paediatrics, West China Second University Hospital, Sichuan University, Chengdu, China, ${ }^{2}$ Division \\ of Oncology Research, Schulze Center for Novel Therapeutics, Mayo Clinic, Rochester, MN, United States
}

Retrograde transport from endosomes to the trans-Golgi network (TGN) diverts proteins and lipids away from lysosomal degradation. It is essential for maintaining cellular homeostasis and signaling. In recent years, significant advancements have been made in understanding this classical pathway, revealing new insights into multiple steps of vesicular trafficking as well as critical roles of ER-endosome contacts for endosomal trafficking. In this review, we summarize up-to-date knowledge about this trafficking pathway, in particular, mechanisms of cargo recognition at endosomes and vesicle tethering at the TGN, and contributions of ER-endosome contacts.

Keywords: endosome, TGN, human disease, membrane trafficking, membrane contact site, golgin, WASH complex, TBC1D23

\section{INTRODUCTION}

Endosomes are central collecting stations in cells where different trafficking pathways converge. Integral membrane proteins, together with their associated proteins and lipids, arrive at endosomes following internalization at the cell surface, and others are transported to endosomes from the trans-Golgi network (TGN) (Burd and Cullen, 2014). One of the major functions of endosomes is "sorting," a term referring to some endosomal proteins and lipids being delivered to the cell surface, via the recycling endosomes, or to the TGN, before reaching the degradative lysosomes (Figure 1). The former pathway is known as endosome-to-plasma membrane recycling, whereas the latter is referred to as endosome-to-TGN retrieval or retrograde transport. Endosomal sorting is crucial for maintaining cellular homeostasis and supporting organism development and growth. Accordingly, many human diseases, including neurological diseases, cancer, and diabetes, have been linked with defects in endosomal functions (Burd and Cullen, 2014; Lucas and Hierro, 2017; McMillan et al., 2017).

The endosome-to-TGN trafficking pathway diverts proteins and lipids away from lysosomal degradation. Mechanistically, this process can be divided into several interconnected steps (Lu and Hong, 2014; Cheung and Pfeffer, 2016; Saimani and Kim, 2017): (1) recognition of endosomal proteins, often in a sequence-dependent manner, by specific protein(s); (2) formation of cargo-enriched endosomal structures/subdomains; (3) endosomal fission leads to the formation of tubulo-vesicular transport carriers; (4) movement of these carriers toward TGN along cytoskeletal tracks; (5) carrier capturing by tethering proteins localized on the TGN; (6) carrier fusion with the Golgi membrane, mediated by the SNARE complex. Recent studies have provided important insights into these steps, including identification of new protein complexes mediating sequence-dependent cargo recognition, 
identification and characterization of multiple regulatory protein complexes, and discovery of new tethering mechanisms at the TGN (McNally et al., 2017; Shin et al., 2017; Navarro Negredo et al., 2018; Simonetti et al., 2019; Singla et al., 2019).

Endosomes function via contacting and fusing with other endosomes or the incoming vesicles that arrive from the Golgi. In addition, non-fusogenic organelle-organelle interactions likely play a role in endosomal trafficking. Endosomes communicate with other organelles through membrane contact sites (MCSs). Most notably, tubules emanating from the endoplasmic reticulum (ER) contact endosomes within a distance of $30 \mathrm{~nm}$ or shorter. The ER-endosome MCSs function to regulate endosome fission, endosome positioning, and cholesterol and $\mathrm{Ca}^{2+}$ transfer (Raiborg et al., 2015). In this review, we summarize critical organelle-organelle and organelle-vesicle interactions in the endosome-to-TGN trafficking. We focus on recent advances in understanding recognition of cargo for retrieval, regulation of endosomal fission by ER-endosome contacts, and finally capturing of endosomal carriers at the TGN, in mammalian cells. We will also discuss the relevance of these processes for human development and disease. Due to space limitations, we are unable to cover every aspect of this trafficking pathway. Readers are invited to look through several recently published reviews that cover aspects not discussed here (Burd and Cullen, 2014; Lu and Hong, 2014; Raiborg et al., 2015; Liu, 2016; Lucas and Hierro, 2017; McMillan et al., 2017; Cullen and Steinberg, 2018).

\section{CARGO RECOGNITION AT ENDOSOMES}

The endosome-to-TGN trafficking pathway is one of two major routes that diverge from lysosomal degradation. Endosomal proteins are delivered to the TGN through two distinct itineraries: from either the early endosome/recycling endosome or the late endosome (Ghosh et al., 1998; Mallet and Maxfield, 1999). Proteins transiting this pathway include members of the Vps10 domain family cargo receptors (such as sortilin and SorLA/SorL1) (Nielsen et al., 2001; Willnow and Andersen, 2013), cation-dependent or cation-independent mannose-6phosphate receptor (CD-MPR or CI-MPR) (Meyer et al., 2000; Schweizer et al., 2000; McKenzie et al., 2012), enzymes such as endoprotease furin and carboxypeptidase D (Varlamov and Fricker, 1998), and TGN38/46 (Ghosh et al., 1998). Furthermore, bacterial and plant toxins, such as Shiga toxin, Cholera toxin, and Ricin, hijack this pathway for their intracellular traveling before reaching the ER (Sandvig and van Deurs, 2002; Mukhopadhyay and Linstedt, 2012).

A number of proteins have been shown to mediate sequencespecific sorting to the TGN, including retromer (Seaman, 2018), SNX-BARs (Kvainickas et al., 2017a; Simonetti et al., 2017, 2019), clathrin and adaptors (Hirst et al., 2012, 2013), Rab9 GTPase and TIP45 (Carroll et al., 2001), and PACS-1 (Wan et al., 1998).

\section{Retromer}

Retromer was initially found to mediate endosome-to-TGN transport of Vps10 in yeast (Seaman et al., 1998; Nothwehr et al., 2000). Similarly, mammalian retromer (VPS35/VPS26/VPS29) has been shown by multiple groups to mediate the transport of CI-MPR, the functional equivalent of Vps10, and other cargo proteins, likely through a direct interaction (Arighi et al., 2004; Seaman, 2004). It is reported that a sequence comprising TrpLeu-Met (WLM) present in the cytoplasmic tail of CI-MPR is required to associate with retromer and for the endosome-toGolgi retrieval of CI-MPR (Seaman, 2007).

Multiple distinct cargo-recognizing mechanisms have been discovered. For instance, yeast Vps10 contains a bipartite signal that is recognized by the retromer subunit Vps35 and Vps26 (Suzuki et al., 2019). In mammals, the SNX3-retromer complex mediates the transport of wntless, DMT1 (divalent metal transporter 1), and CI-MPR, via recognizing the aromatic, hydrophobic motif in their cytoplasmic tails (Harterink et al., 2011; Zhang et al., 2011; Harrison et al., 2014; Lucas et al., 2016; Cui et al., 2019). Crystal structure of the quaternary VPS35VPS26-SNX3-DMT1 tail complex revealed that VPS26 and SNX3 cooperate to mediate cargo recognition (Lucas et al., 2016). Cargo recognition is achieved through a different mechanism for another cargo protein, SorLA. It has been shown that VPS26 on its own binds to the FANSHY sorting motif presented in SorLA, although structural evidence remains to be established (Fjorback et al., 2012).

\section{SNX-BAR Proteins}

The SNX-BAR proteins belong to the PX (phox-homology) domain and SNX (sorting nexin) protein family (Teasdale and Collins, 2012). They contain a BAR (Bin/Amphiphysin/Rvs) domain, in addition to the PX domain. The retromer-related SNX-BAR proteins (referred to as SNX-BARs herein) function as a heterodimer, through the interaction between SNX1 or SNX2, and SNX5 or SNX6 or SNX32 (Carlton et al., 2004; Wassmer et al., 2007). Traditionally, SNX-BARs are regarded as a membrane-binding module to facilitate retromer-mediated cargo recognition and retrieval. The presence of two membraneinteracting domains in SNX-BARs enables coincidence detection of PI3P (phosphatidylinositol 3-phosphate), by the PX domain of SNX1/2, and membrane curvature, by the BAR domain (Teasdale and Collins, 2012). Recently, two independent studies reveled that SNX-BARs can directly associate with CI-MPR to mediate its retrieval (Kvainickas et al., 2017a; Simonetti et al., 2017). Moreover, these studies also showed that deletion of VPS35, unlike deletion of SNX-BARs, did not cause a pronounced defect in CI-MPR trafficking (Kvainickas et al., 2017a; Simonetti et al., 2017). Cargo proteins recognized and transported by SNX-BARs are not limited to CI-MPR, and now the list of cargoes includes IGF1R, SEMA4C, and dozens of other integral membrane proteins, which undergo either endosome-to-TGN or endosome-to-plasma membrane trafficking (Kvainickas et al., 2017a; Simonetti et al., 2017, 2019; Bareja et al., 2018).

The SNX-BAR proteins recognize a bipartite sorting signal $[\Phi \mathrm{X} \Omega \mathrm{X}(\mathrm{X}) \mathrm{n} \Phi, \Phi$, hydrophobic residues; $\mathrm{X}$, any residue; $\Omega$, aromatic residues] in cargo proteins (Simonetti et al., 2019). Interestingly, the WLM motif in the cytoplasmic tail of CI-MPR is part of the soring signal recognized by SNXBARs. The PX domain of SNX5/SNX6/SNX32 contains a long 


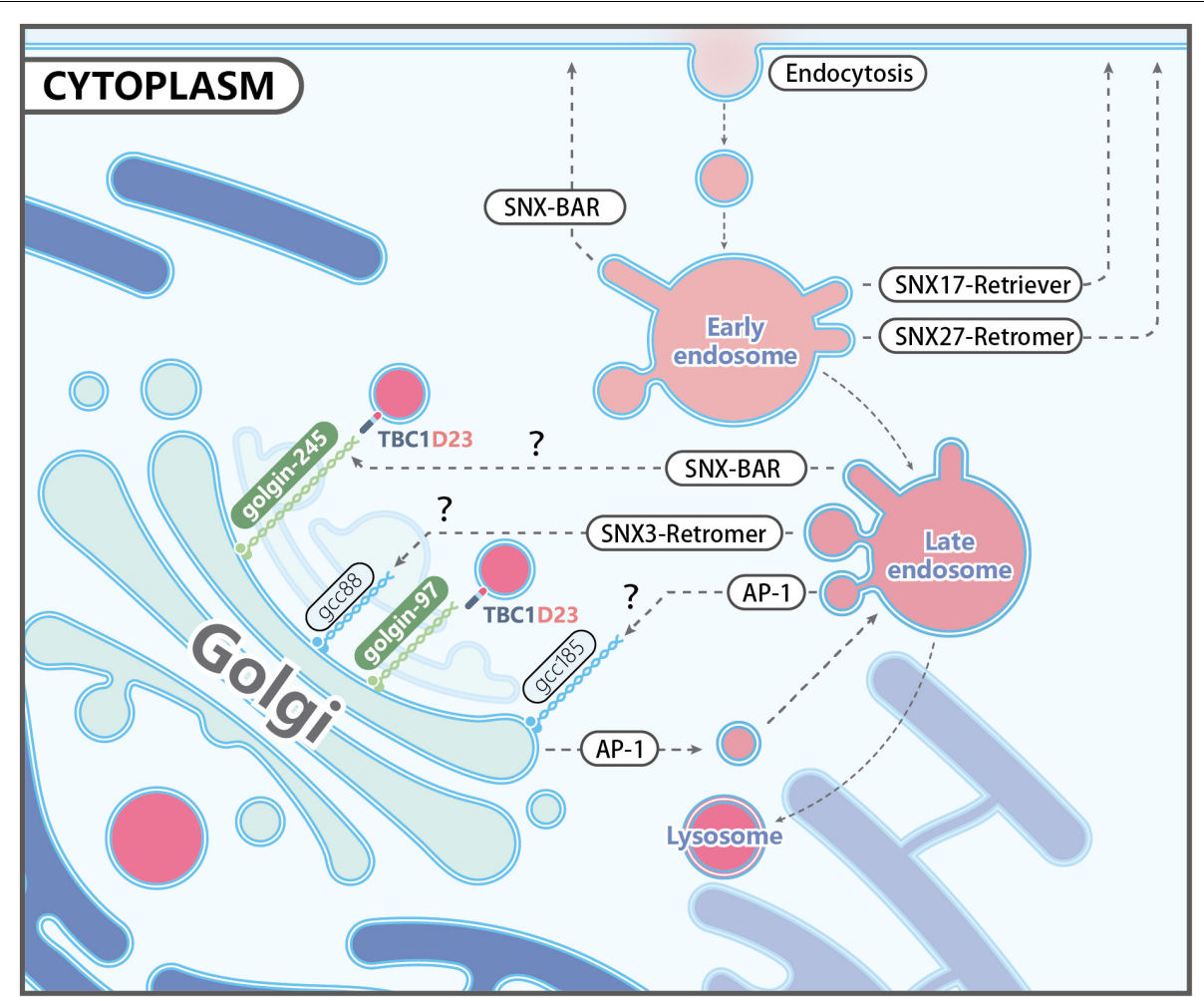

FIGURE 1 | Representative trafficking pathways of transmembrane proteins. Transmembrane receptors are internalized via endocytosis, and some of them are targeted to lysosomes as endosomes mature. Other receptors are recognized by specific coat proteins and sorted to the plasma membrane or the trans-Golgi network (TGN), thus evading degradation. Known protein complexes involved in endosome-to-plasma membrane trafficking include SNX17-retriver, SNX27-retromer, and SNX-BARs. Endosome-to-TGN transport depends on cargo recognition mediated by SNX3-retromer, SNX-BARs, or Clathrin/AP1. Other proteins mediating endosome-to-TGN trafficking, including other Adaptor Proteins, Rab9, TIP47, and PACS-1, are not shown for simplicity. The TGN-localized golgin proteins, such as golgin-97, golgin-245, GCC88, and GCC185, are capable of capturing distinct types of endosomal carriers, although the specificity and underlying mechanisms are largely unknown. TBC1D23 acts as an adapter by interacting with golgin-97 and golgin-245, and the WASH complex subunit FAM21 on endosomal vesicles. It should be noted that AP-1 is also found at the TGN, and mediates the bi-directional trafficking between endosomes and the TGN.

insertion relative to other PX domains, and does not bind to phosphoinositides, such as PI3P (Chandra et al., 2019). Instead, this insertion, together with a proximal $\beta$-strand, constitute the binding site for the sorting signal, which forms two antiparallel $\beta$-strands (Simonetti et al., 2019). Interestingly, structure of the sorting signal in the complex resembles that of the Chlamydia trachomatis effector protein IncE (Elwell et al., 2017; Paul et al., 2017; Sun et al., 2017).

Is CI-MPR a cargo of retromer, or SNX-BARs? Current evidence suggests two possible models. The first model suggests that retromer and SNX-BARs mediate two independent pathways for CI-MPR retrieval. Supporting this model is the observation that retromer and SNX3, and SNX-BARs, mediate CI-MPR transport in carriers that depend on different tether proteins on the TGN (see later) (Cui et al., 2019). The second model supports that SNX-BARs play a dominant role in CIMPR trafficking, whereas retromer regulates CI-MPR trafficking through interacting with TBC1D5 and modulating the activity of Rab7 GTPase (Jia et al., 2016; Jimenez-Orgaz et al., 2018; Kvainickas et al., 2019). Consistent with this model, Steinberg et al. (2013) showed that deletion of VPS35, although not having a pronounced effect on the subcellular localization of CI-MPR, altered the transportation kinetics of endocytosed CI-MPR to the TGN (Kvainickas et al., 2017a). Distinguishing these two models represent an exciting direction in the field.

\section{Clathrin and Adapters}

In addition to retromer and SNX-BARs, clathrin and its adaptor proteins are also involved in endosome-to-TGN trafficking. Clathrin associates with two types of adaptor proteins: tetrameric and monomeric. The former includes five Adaptor Proteins: AP1, AP-2, AP-3, AP-4, and AP-5. All of them, excepted for AP-2, participates in endosomal trafficking (Park and Guo, 2014). The monomeric adaptor proteins include epsinR and GGA (Golgilocalized, $\gamma$-adaptin ear-containing, Arf-binding). Among all the adaptor proteins associating with clathrin, AP-1 and epsinR have the most established roles in CI-MPR retrieval to the TGN. Unlike retromer, AP-1 and epsinR localize on both endosomes and the TGN (Meyer et al., 2000). Depletion of AP-1 or epsinR results in a dispersed MPR localization pattern, consisting with defects in endosome-to-TGN transport (Meyer et al., 2000; Hirst et al., 2004; Saint-Pol et al., 2004; Robinson et al., 2010). These results are further supported by rapid depletion of AP-1 by the "knocksideways" system, which reveals AP-1 affects a large 
number of proteins, including lysosomal hydrolases and their receptors (MPR), various SNAREs, and many integral membrane proteins (Hirst et al., 2012). AP1 could directly bind cargos by interacting with $\mathrm{YXX} \Phi$ and [DE]XXXL[LI] motifs in their cytosolic tails (Rapoport et al., 1998). In addition to AP-1, AP5 is also implicated in the retrieval of CI-MPR (Hirst et al., 2013). Although retromer, SNX-BARs, and clathrin are all involved in the endosome-to-TGN trafficking, it remains obscure whether they function together or separately, and whether they function sequentially or concurrently.

\section{ER-ENDOSOME CONTACT SITES AND ENDOSOME FISSION}

\section{ER-Endosome Contact Sites}

The ER is a continuous network of tubules and cisternae that have versatile cellular functions, including protein synthesis and transport, lipid metabolism, calcium storage, and stress response. This network spreads throughout the cytoplasm, physically separated from other membrane compartments but functionally connected with organelles of the endocytic pathway, the nuclear membrane, and the plasma membrane (Wu et al., 2018). In addition to vesicular trafficking, MCSs have emerged as an alternative means of inter-organelle communication between the ER and other intracellular membranes. One developing theme is that each type of MCS has a unique molecular composition with unique functions (Raiborg et al., 2015; Wu et al., 2018).

\section{ER-Endosome Contact Sites Regulate Endosome Fission}

Endosome fission is the step whereby membrane carriers, including vesicles and tubules, bud and split from endosomes. It is critical for recycling of cargoes to the plasma membrane or TGN, and important for endosome maturation. ER tubules were initially found at the sites of mitochondria division (Friedman et al., 2011), and Rowland et al. demonstrated that ER-endosome contact sites are also required for endosome fission (Rowland et al., 2014). ER tubules make contact with the endosome, marked by the WASH complex subunit FAM21, just before the fission event (Rowland et al., 2014). Consistently, altered shape and dynamics of ER by overexpression of Reticulon $4 \mathrm{a}$, which is known to generate ER tubules, results in a significantly decreased number of endosome buds undergoing fission (Shibata et al., 2008; Rowland et al., 2014).

Given the immediate establishment of ER-endosome contact sites prior to fission, these contact sites might be extremely transient, thus hampering the identification of its molecular composition. Using a proximity biotinylation assay in which FAM21 was tagged, Hoyer et al. identified the ER transmembrane protein TMCC1 as a critical protein mediating the ERendosome contact (Hoyer et al., 2018). Depletion of TMCC1 specifically impairs fission of endosomal tubules and subsequent cargo sorting, but does not alter the formation of these tubules, emphasizing the importance of ER-endosome MCSs in endosome fission. Hoyer et al. further demonstrated that endosome-localized Coronin $1 \mathrm{C}$ is involved in ER-mediated endosome fission (Hoyer et al., 2018). Coronin $1 \mathrm{C}$ is an actin-binding protein that has been shown to accumulate at sites of Arp2/3-generated actin patches on endosomes (Puthenveedu et al., 2010). Interestingly, depletion of Coronin 1C prevented TMCC1 recruitment leading to a dramatic reduction in ER-endosome contacts and defective endosome fission of WASH-labeled endosomal buds (Hoyer et al., 2018; Figure 2). Since Coronin proteins are known to mediate F-actin disassembly by displacing Arp2/3 complexes, Coronin 1C might function to not only recruit TMCC1/ER MCSs, but to also simultaneously disassemble branched F-actin at the site of endosomal fission (Figure 2).

In addition to TMCC1 and Coronin 1C, the ER-endosome MCSs can be also mediated by ER protein VAP (vesicle-associated membrane protein-associated protein, including VAP-A and VAP-B) and two proteins localized on endosomes: SNX2 and OSBP (Oxysterol Binding Protein) (Dong et al., 2016). Loss of VAP or OSBP results in increased PI4P and actin levels on endosomes, and leads to defective endosome-to-Golgi traffic (Dong et al., 2016). It remains to be determined whether the loss of VAP or OSBP decreases endosome budding or subsequent bud fission.

From a mechanistic standpoint, it is unclear how ERendosome MCSs contribute to scission of endosomal tubules. It is likely that some fission proteins are recruited to these sites to facilitate scission. Interesting candidates include Dynamin2 and the EHD (Eps15 homology domain) proteins, which could provide the mechanochemical force required for the fission. Dynamin2 has been reported to interact with the WASH complex, indicating a putative role for the scission of tubules (Derivery et al., 2009). The human genome encodes four EHD proteins, which share the conserved EHD domain. Structural studies of EHD2 reveals that the EHD domain forms ringlike oligomers around tubules, similar to the Dynamin GTPase (Daumke et al., 2007). It has been shown that EHD1 associates with retromer, and stabilizes the membrane tubules generated by SNX1 (Gokool et al., 2007; Zhang et al., 2012). Thus, Dynamin2 and EHD proteins may function together with the WASH complex to promote endosomal fission at the ERendosome MCSs.

\section{ER-Endosome MCSs and Human Diseases}

Emphasizing the importance of ER-endosome MCSs for human health is the observation that mutations or aberrant expression of corresponding genes have been linked with many types of human diseases. Hereditary spastic paraplegia (HSP) is a group of inherited diseases characterized by progressive stiffness in the lower limbs. Among the over 60 genes that have been linked with HSP (Hensiek et al., 2015), many of them are implicated in the formation of ER-endosome MCSs, such as REEP1, WASH complex subunit strumpellin, ER protein protrudin, and spastin (Beetz et al., 2006, 2008; Mannan et al., 2006; Valdmanis et al., 2007). For instance, spastin is an 

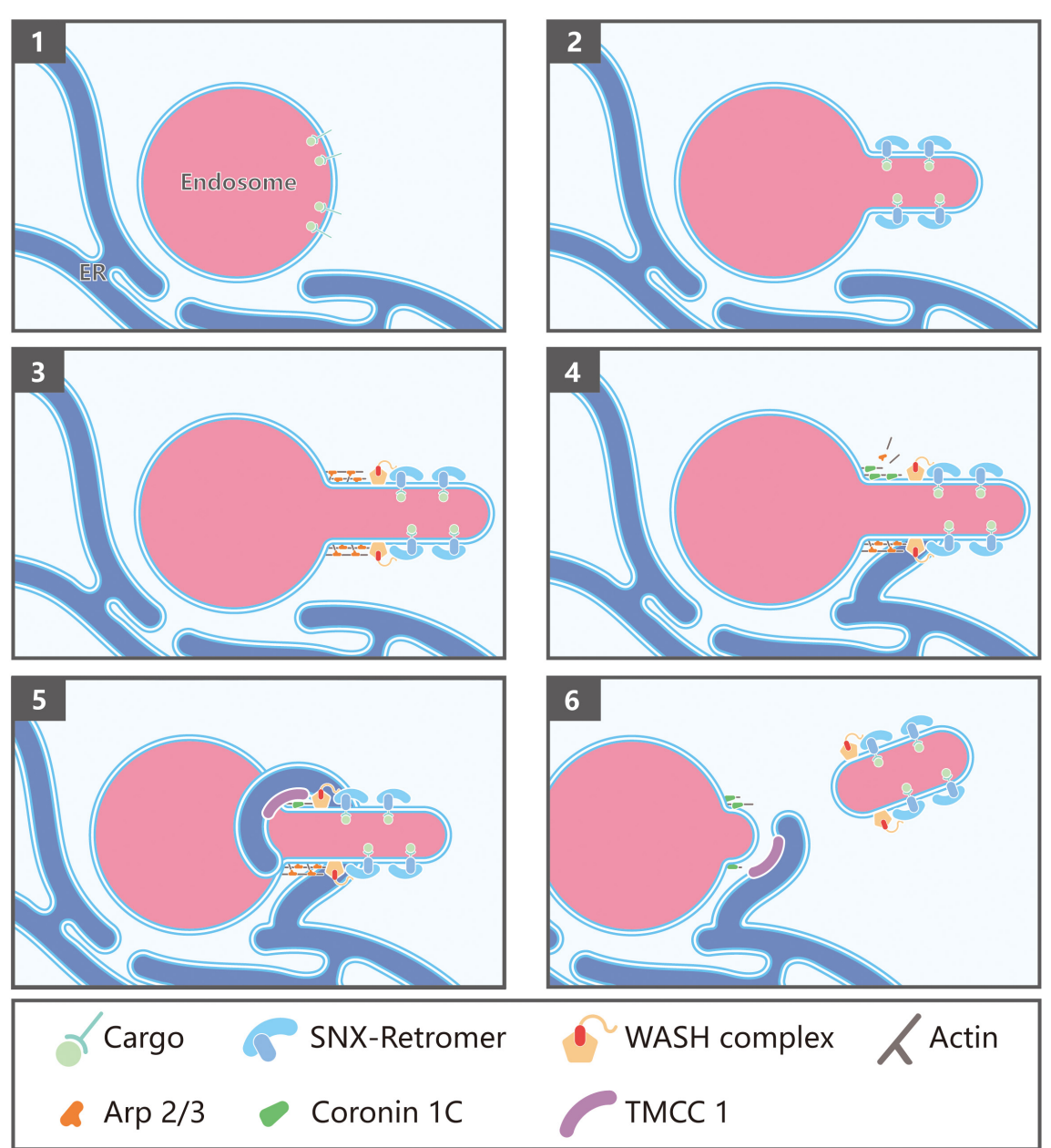

FIGURE 2 | Endoplasmic reticulum (ER)-endosome membrane contact sites in endosome fission: (1) Endosomes contain internalized transmembrane proteins or proteins delivered from the Golgi; (2) protein complexes, such as SNXs and retromer, recognize and concentrate specific cargo, and promote membrane remodeling; (3) retromer recruits the WASH complex via a direct interaction with the FAM21 subunit, which in turn promotes the assembly of branched actin via Arp2/3; (4) Coronin $1 \mathrm{C}$ associates with Arp2/3-mediated actin patches present on endosome buds; (5) Coronin 1C interacts with the ER membrane protein TMCC1 in order to recruit the ER to the Coronin $1 \mathrm{C}$-labeled endosomal domains; (6) endosome fission occurs, likely via fission factors whose identity remains to be determined. Possible candidates include Dynamin2 and the EHD family proteins.

AAA family ATPase and functions as a microtubule severing protein (Roll-Mecak and Vale, 2008). The ER-localized spastin isoform mediates ER-endosome MCSs through interacting with the ESCRT-III protein IST1, which is critical for sorting of mannose 6-phosphate receptor and consequently lysosomal enzyme trafficking (Allison et al., 2017). Accordingly, abnormal lysosomal morphology has been observed in neurons and other types of cells that are depleted of not only spastin, but also REEP1 and strumpellin, suggesting that aberrant ERendosome contacts likely contribute to the pathogenesis of HSP (Allison et al., 2017).

In addition to HSP, dysregulation of ER-endosome MCSs are implicated in other diseases. For instance, Niemann-Pick diseases are a group of metabolic diseases, in which large quantities of lipids accumulate in the spleen, liver, brain, and other parts of the body. Mutations of NPC1 (NiemannPick C1), which mediates the ER-late endosome contacts, and NPC2 (Niemann-Pick C2), result in failed cholesterol transport from the endosomal lumen and lead to NiemannPick disease (Carstea et al., 1997; Goldstein and Brown, 2001; Sleat et al., 2004).

\section{CAPTURING ENDOSOMAL CARRIERS AT THE TGN}

Transported vesicles destined for the Golgi are captured by tethering factors at a long distance (could extend for 100$400 \mathrm{~nm}$ ), before subsequent vesicle docking and fusion mediated by the SNARE complex. Tethering factors localized on the Golgi can be divided into two classes: large oligomeric complexes including Golgi-associated retrograde protein (GARP) and conserved oligomeric Golgi (COG), and homodimeric golgin proteins (Whyte and Munro, 2002; Yu and Hughson, 2010). 


\section{GARP and COG}

Both GARP and COG are recruited to the Golgi via interaction with small GTPases of the Rab and Arl families. COG is an octamer localized in all Golgi cisternae and plays a role in the retrieval of resident proteins between stacks (Zolov and Lupashin, 2005; Ungar et al., 2006). COG mutations have been linked with congenital disorders of glycosylation (CDG) (Zeevaert et al., 2008). The GARP complex (VPS51, VPS52, VPS53, and VPS54), mainly found at the TGN, is involved in transport of cargoes including the late-Golgi SNAREs and CI-MPR (Conibear et al., 2003; Perez-Victoria et al., 2008). This trafficking pathway is further stimulated by amino acids, requiring the small GTPase Arl5 and the Ragulator complex. Arl5 enhances the membrane recruitment of the GARP complex, and Ragulator may function as a guanine nucleotide exchange factor for Arl5 (Shi et al., 2018).

\section{Golgins}

Golgins represent another class of tethering proteins at the Golgi. Highly conserved among eukaryotes, golgins feature a long coiled-coil structure. The number of golgin-encoding genes has expanded during evolution, with 5 and more than 10 golgin-encoded genes in the $S$. cerevisiae and human genomes, respectively (Munro, 2011). The large number of golgin proteins is consistent with their diverse cellular functions. Using a mitochondrial re-location assay, Munro et al., found that golgin proteins could capture distinct sets of Golgi-bound transport vesicles (Wong and Munro, 2014). For instance, GM130 and GMAP-210 that localize in the cis-Golgi are capable of tethering vesicles arriving from the ER. The TGN-localized golgins, golgin97, golgin-245, and GCC88, capture vesicles from endosomes; GCC185 did not capture vesicles in the assay (Wong and Munro, 2014). However, a separate study showed that GCC185 contains an AP-1 binding site and likely involves tethering of AP-1decorated vesicles (Brown et al., 2011).

Different golgin proteins localize in different parts of the Golgi stack, and four mammalian golgins localize at the TGN: golgin-97, golgin-245, GCC88 and GCC185 (Figure 1). They share a conserved domain of about 80 residues at their carboxyl terminus, called the GRIP domain. The GRIP domain binds to the activated Arl1 GTPase localized at the TGN, which is critical for the Golgi-targeting of these golgins (Witkos and Lowe, 2015; Gillingham and Munro, 2016). In addition to Arl1 GTPase, these golgins also harbor binding sites for a variety of proteins, including AP-1, Rab GTPases, motor proteins and SNAREs (Derby et al., 2007; Burguete et al., 2008; Miller et al., 2009; Brown et al., 2011). These interactions allow golgins to capture specific transport vesicles from a long distance, as some golgins have a length of over $100 \mathrm{~nm}$, and subsequently tether vesicles to the destination membrane.

One emerging concept in the field is that there are some degrees of crosstalk between the proteins involved in cargo recognition and carrier formation, and those involved in vesicle tethering (Figure 1). For instance, Cui et al. showed that SNX3and retromer-dependent CI-MPR carriers are recognized and captured by GCC88, but not by golgin-97 or golgin-245 (Cui et al., 2019). On the other hand, SNX-BARs mediate CI-MPR trafficking in carriers that are captured by golgin-245 (Cui et al., 2019). It will be highly informative to determine how different types of carriers are recognized by different tethers.

\section{TBC1D23}

Three golgins mediate endosome-to-TGN transport: golgin97, golgin-245, and GCC88 in the mitochondrial re-location assay (Wong and Munro, 2014). How these golgin proteins capture transport vesicles from endosomes remained unclear until recently. Earlier studies suggested that the N-termini of golgins are required to capture correct vesicles by interacting with vesicle-specific proteins or lipids (Wong and Munro, 2014). Using the mitochondrial re-location and proximity biotinylation assays, Shin et al. identified that the N-termini of golgin-97 and golgin-245, but not GCC88, interact with TBC1D23 (Shin et al., 2017). TBC1D23 also interacts with the WASH complex subunit FAM21, which is localized on vesicles derived from endosomes (Shin et al., 2017). Thus, TBC1D23 functions as an adapter to bridge endosomal vesicles with the TGN.

TBC1D23 is a member of the Tre2-Bub2-Cdc16 (TBC) family and can be found in most eukaryotic organisms, except for fungi and plants (Shin et al., 2017). The wide distribution and ubiquitous expression of TBC1D23 in various tissues and cells are consistent with its fundamental roles in biology and in development. Two human TBC1D23 isoforms are described so far, which differ by one exon (exon 15). As a result, the longer isoform including this exon encodes a protein with 699 residues, and the shorter one encodes 684 residues (MarinValencia et al., 2017). TBC1D23 contains three functional domains: an N-terminal TBC domain, a Rhodanese-like domain in the middle, and an C-terminal domain which is shown to be structurally similar to a Pleckstrin homology $(\mathrm{PH})$ domain (Figure 3A; Wang et al., 2018; Huang et al., 2019). Its TBC domain interacts with the N-terminal 21 residues from golgin97 or golgin-245 (Shin et al., 2017). Members of the TBC family often function as Rab GTPase-activating proteins (GAPs), and contain two conserved catalytic residues, Arg and Gln within their GAP domain (Pan et al., 2006). For instance, TBC1D5 is a GAP for both Rab7a and Rab7b, and functions to regulate retromer-dependent trafficking, and to regulate late endosomal and lysosomal functions (Figure 3A; Mukhopadhyay et al., 2007; Seaman et al., 2009; Jia et al., 2016; Borg Distefano et al., 2018; Jimenez-Orgaz et al., 2018; Kvainickas et al., 2019). In contrast, TBC1D23 lacks both essential catalytic residues, and is catalytically inactive (Marin-Valencia et al., 2017). Proteins with a rhodanese domain can possess sulphurtransferase (such as TSTD1) or phosphatase (such as CDC25) activity (Bordo and Bork, 2002). It remains to be determined whether the rhodanese domain of TBC1D23 possesses any enzymatic activities; if it does, how the enzymatic activities contribute to its functions in membrane trafficking remains to be determined. Finally, we recently solved the crystal structure of the TBC1D23 C-terminal domain, and showed that it selectively binds to phosphoinositides, including PI4P, and the FAM21 subunit of the WASH complex, using opposite surfaces (Huang et al., 2019). Whereas these observations are interesting, additional work is needed to address whether such interactions help to 
A

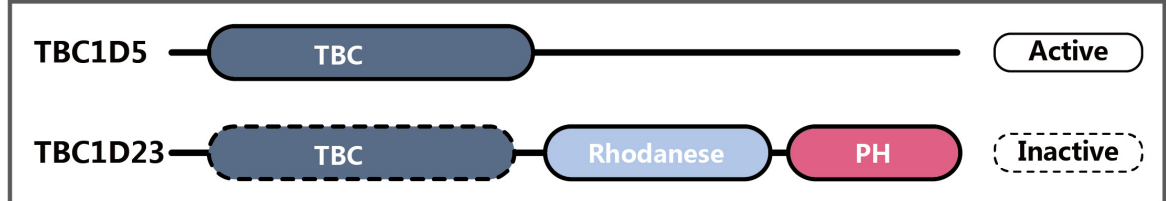

B
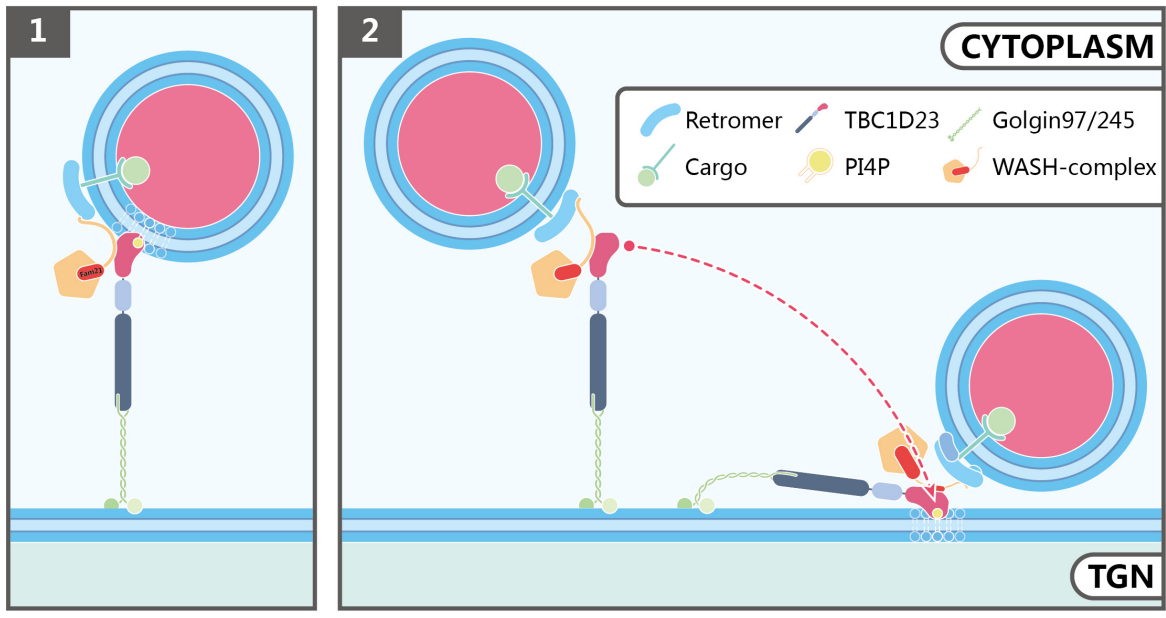

FIGURE 3 | Possible functions of TBC1D23 in endosome-to-TGN trafficking. (A) Domain structures of TBC1D5 and TBC1D23. Although both proteins possess a TBC domain, TBC1D5, but not TBC1D23, is an active GAP for Rab GTPases. In addition to the TBC domain, TBC1D23 also contains a rhodanese-like domain, and a C-terminal domain, which is structurally similar to phospholipid-binding PH domains despite bearing little sequence similarity. (B) Models showing how TBC1D23 regulates endosome-to-TGN trafficking by interacting with FAM21 and specific phosphoinositides, such as PI4P. FAM21 associates with WASH, TBC1D23 and retromer via its $\mathrm{N}$-terminus, the middle region, and C-terminus, respectively. Whereas the C-terminal domain of TBC1D23 engages with PI4P, in addition to FAM21, future studies will be needed to address whether such interactions help to capture the PI4P-positive endosomal vesicles by TBC1D23 (1), or promote the tethering of TBC1D23-bound vesicles to the TGN (2).

capture the PI4P-positive endosomal vesicles by TBC1D23, or promote the tethering of TBC1D23 and bound vesicles by the TGN (Figure 3B).

Emphasizing the importance of TBC1D23 in human development, homozygous mutations of the TBC1D23 gene has recently been found in patients diagnosed with pontocerebellar hypoplasia (PCH) (Ivanova et al., 2017; Marin-Valencia et al., 2017; Harripaul et al., 2018). These mutations result in truncated proteins that are missing the $\mathrm{C}$-terminal domain. $\mathrm{PCH}$ is a group of neurological disorders, characterized by the impaired development of the brain, especially the pons and the cerebellum. Other features of $\mathrm{PCH}$ patients include delayed development, microcephaly, movement problems, and intellectual disability. Interestingly, most of the genes linked with $\mathrm{PCH}$ are involved in RNA processing (Namavar et al., 2011; Rudnik-Schoneborn et al., 2014), unlike TBC1D23. Using cellular assays and zebrafish models, we demonstrated a strong correlation between cellular and zebrafish phenotypes caused by different TBC1D23 mutants, indicating that mis-regulation of cargo trafficking from endosomes, at least partially, contributes to the development of PCH (Huang et al., 2019). Future studies will be necessary to determine which cargo proteins are most severely affected by TBC1D23 deletion or mutations, which could provide fresh insights into the pathogenesis of certain types of PCH.

\section{WDR11}

In addition to goglin-97, golgin-245, and FAM21, TBC1D23 also interacts with a trimeric complex, consisting of WDR11, FAM91A, and C17orf75, through a region between the rhodanese and PH domains (Borner et al., 2014; Shin et al., 2017; Navarro Negredo et al., 2018). The WDR11 complex is proposed to function together with TBC1D23 and the clathrin adaptor, AP1 , to promote endosome-to-TGN trafficking (Navarro Negredo et al., 2018). One possibility is that WDR11 localizes on the TGN and functions to capture vesicles containing AP-1-dependent cargo; the other possibility is that WDR11 associates with the vesicle, and its interaction with TBC1D23 promotes vesicle tethering at the TGN (Navarro Negredo et al., 2018). Either scenario is consistent with some tethering roles of TBC1D23 and the WDR11 complex, although the exact mechanisms remain to be determined.

Intriguingly, mutations of WDR11 have been found in patients with congenital hypogonadotropic hypogonadism $(\mathrm{CHH})$ and Kallmann syndrome (KS), developmental disorders characterized by delayed puberty and infertility (Kim et al., 2010). WDR11 is essential for normal ciliogenesis, by being involved in the Hedgehog (Hh) signaling pathway (Kim et al., 2018). However, it is unclear whether TBC1D23 is also involved in these processes. 


\section{WASH COMPLEX}

One molecule recurring through many distinct processes of endosomal trafficking is the evolutionarily conserved WASH complex, which promotes endosomal branched actin polymerization (Derivery et al., 2009; Gomez and Billadeau, 2009; Jia et al., 2010). In cells, WASH forms a stable pentameric complex together with four other proteins, including FAM21 (WASHC2), CCDC53 (WASHC3), SWIP (Strumpellin and WASH1-interacting protein or WASHC4), and Strumpellin (WASHC5) (Derivery et al., 2009; Jia et al., 2010). The WASH complex predominantly localizes to endosomes and functions to regulate multiple endosomal trafficking pathways. Among them, the best-characterized function of WASH is to regulate retromer-dependent trafficking through an association with retromer, via a direct interaction between the retromer subunit VPS35 and FAM21 (Harbour et al., 2010; Jia et al., 2012). WASH modulates endosome-to-TGN or endosome-to-plasma membrane transport of many endosomal proteins, such as CI-MPR, the $\beta 2$-adrenoceptor ( $\beta 2 \mathrm{AR}$ ), the glucose transporter GLUT1, and transferrin receptor (TfnR) (Derivery et al., 2009; Puthenveedu et al., 2010; Zech et al., 2011; Gomez et al., 2012; Piotrowski et al., 2013; Phillips-Krawczak et al., 2015). Recent studies demonstrate that the WASH complex also functions to orchestrate retromer-independent trafficking, by cooperating with retriever and the CCC complex (McNally et al., 2017). In addition to retromer, HRS (hepatocyte growth factorregulated tyrosine kinase substrate) also plays a role in regulating endosomal localization of WASH, although it is unclear whether the interaction between WASH and HRS is direct (MacDonald et al., 2018). It is reported that WASH and HRS cooperate to regulate endosomal recycling of epidermal growth factor receptor and the matrix metalloproteinase MT1-MMP (MacDonald et al., 2018). The WASH complex also associates with BLOC-1 (biogenesis of lysosomal organelles complex-1), and may play a role in the formation of melanosomes (Monfregola et al., 2010; Ryder et al., 2013). In all of the above processes, WASH likely functions to promote actin polymerization and to provide the force required for the formation of endosomal recycling or retrieval subdomains, or for vesicle budding and scission. The WASH complex, especially FAM21, also likely serves as a recruiting hub for additional proteins involved in the trafficking of proteins to specific subcellular destinations (Seaman et al., 2013; Wang et al., 2018).

The WASH complex possesses additional functions. It has been shown that WASH defines endosome fission sites by locally activating the Arp $2 / 3$ complex to generate branched F-actin, and the subsequent recruitment of Coronin 1C, which facilitates interaction with TMCC1 leading to ER-endosome contact (Rowland et al., 2014; Hoyer et al., 2018). Finally, the interaction between endosomal-localized FAM21 and Golgilocalized TBC1D23 promotes vesicle tethering at the TGN (Shin et al., 2017; Huang et al., 2019). How can one protein complex possess so many diverse functions? Part of the answer lies in the fact that FAM21 is a large protein with over 1300 residues. Although slightly over 200 residues within the $\mathrm{N}$-terminus of FAM21 are sufficient for assembly of the WASH pentameric complex, the C-terminal tail of FAM21 harbors 21 repeats of the LFa motif (L-F-[D/E]3-10-L-F), and is capable of engaging several proteins, including retromer, TBC1D23, CCC complex, CapZ, and FKBP15 among others (Hernandez-Valladares et al., 2010; Jia et al., 2010, 2012; Takeda et al., 2010; Harbour et al., 2011, 2012; Freeman et al., 2014; Phillips-Krawczak et al., 2015; Kvainickas et al., 2017b; Shin et al., 2017). Interestingly, although both retromer and TBC1D23 bind to LFa motifs within the FAM21 tail, their different sequence preference allows them to bind non-overlapping motifs (Huang et al., 2019).

Deletion of WASH in mice leads to embryonic lethality, emphasizing the indispensable role of the WASH complex in mammalian development (Gomez et al., 2012; Xia et al., 2013). Interestingly, WASH deletion in Drosophila does not result in lethality, likely due to a compensatory effect of related genes (Verboon et al., 2018). Furthermore, mutations in Strumpellin and SWIP have been linked with multiple neurological disorders, including intellectual disability, hereditary spastic paraplegia, and Ritscher-Schinzel/3C syndrome (Valdmanis et al., 2007; Ropers et al., 2011; Vardarajan et al., 2012; de Bot et al., 2013; Elliott et al., 2013). Finally, an early onset Parkinson's Disease (PD) mutation in VPS35 (D620N) was shown to compromise the interaction between the WASH complex and retromer, and to impair endosomal trafficking as well as autophagy (VilarinoGuell et al., 2011; Zimprich et al., 2011; Follett et al., 2014; McGough et al., 2014; Miura et al., 2014; Zavodszky et al., 2014). Altogether, these studies highlight that regulation of endosomal trafficking via fine-tuning actin polymerization is essential for mammalian development, especially for neuronal development.

\section{AN EVOLUTIONARY PERSPECTIVE}

Although the endosome-to-TGN trafficking is absolutely conserved in eukaryotes, it is interesting to note the divergence of many important genes (Table 1). Whereas retromer, SNX3, SNX-BARs are conserved in the eukaryotic kingdom, many genes encoding proteins with regulatory functions, such as the WASH complex and EHD1, are missing in S. cerevisiae (Seaman, 2012). Similarly, whereas mammals have four golgin proteins localized at the TGN, yeast only has one, IMH1 (Munro, 2011). IMH1 is known to participate Ypt6-mediated, the yeast homolog of mammalian Rab6 GTPase, endosome-to-TGN transport (Chen et al., 2019). However, yeast does not have clear homologs of TBC1D23 or WDR11, suggesting that IMH1 exert its functions through a mechanism distinct from that of golgin-97 and golgin- 245 .

Furthermore, although retromer and SNX-BARs are conserved between yeast and mammals, they show marked differences in many aspects. First, yeast retromer is a stable pentameric complex, consisting of the Vps35-Vps26-Vps29 trimer and the SNX-BAR proteins Vps5 and Vps10 (Seaman et al., 1998). However, in mammals and other higher metazoans, the VPS35-VPS26-VPS29 trimer [referred to as retromer in metazoans (Burd and Cullen, 2014)] and the SNX-BAR dimer function as independent entities, and are only loosely connected with each other. Second, as separate entities, both mammalian 
TABLE 1 | Conservation of selected genes involved in endosome-to-TGN trafficking.

\begin{tabular}{|c|c|c|c|}
\hline & & Homo sapiens & Saccharomyces cerevisiae \\
\hline \multirow[t]{5}{*}{ Coats and related proteins } & Retromer & $\sqrt{ }$ & $\sqrt{ }$ \\
\hline & TBC1D5 & $\sqrt{ }$ & \\
\hline & SNX-BAR & $\sqrt{ }(\mathrm{SNX} 1 / \mathrm{SNX} 2+\mathrm{SNX5/SNX6/SNX32)}$ & $\sqrt{ }($ pps5 + Vps17) \\
\hline & SNX3 & $\sqrt{ }$ & $\sqrt{ }$ \\
\hline & $\mathrm{AP}-1$ & $\sqrt{ }$ & $\sqrt{ }$ \\
\hline \multirow[t]{6}{*}{ Tethers and related proteins } & Golgin-97 & $\sqrt{ }$ & \\
\hline & Golgin-245 & $\sqrt{ }$ & $\operatorname{mb} 1$ \\
\hline & GCC88 & $\sqrt{ }$ & IImII \\
\hline & GCC185 & $\sqrt{ }$ & \\
\hline & TBC1D23 & $\sqrt{ }$ & \\
\hline & WDR11 & $\sqrt{ }$ & \\
\hline \multirow[t]{2}{*}{ Other } & WASH complex & $\sqrt{ }$ & \\
\hline & EHD1 & $\sqrt{ }$ & \\
\hline
\end{tabular}

VPS35-VPS26-VPS29 trimer and the SNX-BAR dimer have gained additional functions. For instance, mammalian VPS35VPS26-VPS29 trimer associates with SNX3 or SNX27 to form functionally distinct entities, independent of SNX-BARs (Harterink et al., 2011; Temkin et al., 2011; Steinberg et al., 2013; Gallon et al., 2014). Similarly, mammalian SNX-BAR dimer, but not the yeast Vps5 and Vps10 dimer, are directly involved in sequence-dependent cargo recognition (Kvainickas et al., 2017a; Simonetti et al., 2017, 2019). Lastly, although yeast retromer is a known regulator of endosome-to-Golgi trafficking, both mammalian retromer and SNX-BARs play critical roles in both endosome-to-TGN and endosome-to-plasma membrane recycling. Thus, although yeast represents an excellent model to investigate the endosome-to-TGN trafficking, cautions must be taken when knowledge learned from different organisms are considered together.

\section{CONCLUSION}

The past a few years have witnessed great advances in the field of endosomal biology. First, multiple types of ER-endosome MCSs have been characterized, with each possessing unique molecular compositions and functions (Raiborg et al., 2015; Wu et al., 2018). ER-endosome contact sites are known to regulate many aspects of endosomal functions, ranging from endosome positioning and fission, to lipid and ion exchange. Second, several new protein complexes, including the SNX17-retriever complex and SNX-BARs, have been discovered to mediate sequencedependent cargo retrieval and recycling (Kvainickas et al., 2017a; McNally et al., 2017; Simonetti et al., 2017, 2019). Third, the mechanisms by which endosomal vesicles are captured by the Golgi are emerging (Cheung et al., 2015; Shin et al., 2017; Navarro Negredo et al., 2018). These advances have greatly expanded our understanding of endosomal trafficking, and provided insight into mechanisms contributing to human disease.

The fast progress made in this field suggests that we can anticipate more exciting developments in the new decade. However, despite the huge leap forward in the field, we are still left with many important questions. For those studying ER-endosome contact, a big question is whether other types of contact sites exist, and what are their functions? How are the dynamics of ER-endosome contact sites regulated? How do ERendosome MCSs promote endosome fission from a mechanistic standpoint? For those interested in vesicular trafficking, it remains to be determined the precise roles and relationship of different molecules involved in cargo recognition and carrier formation, such as retromer, SNX-BARs, and clathrin/AP-1. For most cases, it is still unclear how tethering proteins recognize specific vesicles. Whereas long tethering proteins can capture vesicles as far away as a few hundred nanometers, the SNARE complex mediates vesicle fusion at a much shorter distance $(<10 \mathrm{~nm})$. How does the vesicle tethering step connect with the fusion step? Lastly, as our knowledge increases regarding the molecular mechanisms by which dysregulation of endosomal functions contribute to human disease, the translation of these basic discoveries into the clinic are likely to be rapidly approaching.

\section{AUTHOR CONTRIBUTIONS}

All authors listed have made a substantial, direct and intellectual contribution to the work, and approved it for publication.

\section{FUNDING}

This research was supported by the National Natural Science Foundation of China (NSFC) grants (\#91854121, \#31871429, and \#81901281), National Key Research and Development Program of China (2018YFC1005004), Sichuan Science and Technology Program (2018RZ0128), and US NIH grant (DK107733 to DB).

\section{ACKNOWLEDGMENTS}

We thank members of our laboratory for helpful discussions, and Mr. Chengxin Weng for help with making figures. 


\section{REFERENCES}

Allison, R., Edgar, J. R., Pearson, G., Rizo, T., Newton, T., Gunther, S., et al. (2017). Defects in ER-endosome contacts impact lysosome function in hereditary spastic paraplegia. J. Cell Biol. 216, 1337-1355. doi: 10.1083/jcb.201609033

Arighi, C. N., Hartnell, L. M., Aguilar, R. C., Haft, C. R., and Bonifacino, J. S. (2004). Role of the mammalian retromer in sorting of the cation-independent mannose 6-phosphate receptor. J. Cell Biol. 165, 123-133. doi: 10.1083/jcb. 200312055

Bareja, A., Hodgkinson, C. P., Soderblom, E., Waitt, G., and Dzau, V. J. (2018). The proximity-labeling technique BioID identifies sorting nexin 6 as a member of the insulin-like growth factor 1 (IGF1)-IGF1 receptor pathway. J. Biol. Chem. 293, 6449-6459. doi: 10.1074/jbc.RA118.002406

Beetz, C., Nygren, A. O., Schickel, J., Auer-Grumbach, M., Burk, K., Heide, G., et al. (2006). High frequency of partial SPAST deletions in autosomal dominant hereditary spastic paraplegia. Neurology 67, 1926-1930. doi: 10.1212/01.wnl. 0000244413.49258.f5

Beetz, C., Schule, R., Deconinck, T., Tran-Viet, K. N., Zhu, H., Kremer, B. P., et al. (2008). REEP1 mutation spectrum and genotype/phenotype correlation in hereditary spastic paraplegia type 31. Brain 131(Pt 4), 1078-1086. doi: 10. 1093/brain/awn026

Bordo, D., and Bork, P. (2002). The rhodanese/Cdc25 phosphatase superfamily. Sequence-structure-function relations. EMBO Rep. 3, 741-746. doi: 10.1093/ embo-reports/kvf150

Borg Distefano, M., Hofstad Haugen, L., Wang, Y., Perdreau-Dahl, H., Kjos, I., Jia, D., et al. (2018). TBC1D5 controls the GTPase cycle of Rab7b. J. Cell Sci. 131:jcs216630. doi: $10.1242 /$ jcs. 216630

Borner, G. H., Hein, M. Y., Hirst, J., Edgar, J. R., Mann, M., and Robinson, M. S. (2014). Fractionation profiling: a fast and versatile approach for mapping vesicle proteomes and protein-protein interactions. Mol. Biol. Cell 25, 3178-3194. doi: 10.1091/mbc.E14-07-1198

Brown, F. C., Schindelhaim, C. H., and Pfeffer, S. R. (2011). GCC185 plays independent roles in Golgi structure maintenance and AP-1-mediated vesicle tethering. J. Cell Biol. 194, 779-787. doi: 10.1083/jcb.201104019

Burd, C., and Cullen, P. J. (2014). Retromer: a master conductor of endosome sorting. Cold Spring Harb. Perspect. Biol. 6:a016774. doi: 10.1101/cshperspect. a016774

Burguete, A. S., Fenn, T. D., Brunger, A. T., and Pfeffer, S. R. (2008). Rab and Arl GTPase family members cooperate in the localization of the Golgin GCC185. Cell 132, 286-298. doi: 10.1016/j.cell.2007.11.048

Carlton, J., Bujny, M., Peter, B. J., Oorschot, V. M., Rutherford, A., Mellor, H., et al. (2004). Sorting nexin-1 mediates tubular endosome-to-TGN transport through coincidence sensing of high- curvature membranes and 3-phosphoinositides. Curr. Biol. 14, 1791-1800. doi: 10.1016/j.cub.2004.09.077

Carroll, K. S., Hanna, J., Simon, I., Krise, J., Barbero, P., and Pfeffer, S. R. (2001). Role of Rab9 GTPase in facilitating receptor recruitment by TIP47. Science 292, 1373-1376. doi: 10.1126/science. 1056791

Carstea, E. D., Morris, J. A., Coleman, K. G., Loftus, S. K., Zhang, D., Cummings, C., et al. (1997). Niemann-Pick C1 disease gene: homology to mediators of cholesterol homeostasis. Science 277, 228-231. doi: 10.1126/science.277.5323. 228

Chandra, M., Chin, Y. K., Mas, C., Feathers, J. R., Paul, B., Datta, S., et al. (2019) Classification of the human phox homology (PX) domains based on their phosphoinositide binding specificities. Nat. Commun. 10:1528. doi: 10.1038/ s41467-019-09355-y

Chen, Y. T., Wang, I. H., Wang, Y. H., Chiu, W. Y., Hu, J. H., Chen, W. H., et al. (2019). Action of Arl1 GTPase and golgin Imh1 in Ypt6-independent retrograde transport from endosomes to the trans-Golgi network. Mol. Biol. Cell 30, 1008-1019. doi: 10.1091/mbc.E18-09-0579

Cheung, P. Y., Limouse, C., Mabuchi, H., and Pfeffer, S. R. (2015). Protein flexibility is required for vesicle tethering at the Golgi. eLife 4:e12790. doi: 10.7554/eLife 12790

Cheung, P. Y., and Pfeffer, S. R. (2016). Transport vesicle tethering at the trans Golgi network: coiled coil proteins in action. Front. Cell. Dev. Biol. 4:18. doi: $10.3389 /$ fcell. 2016.00018

Conibear, E., Cleck, J. N., and Stevens, T. H. (2003). Vps51p mediates the association of the GARP (Vps52/53/54) complex with the late Golgi t-SNARE Tlg1p. Mol. Biol. Cell 14, 1610-1623. doi: 10.1091/mbc.e02-10-0654
Cui, Y., Carosi, J. M., Yang, Z., Ariotti, N., Kerr, M. C., Parton, R. G., et al. (2019). Retromer has a selective function in cargo sorting via endosome transport carriers. J. Cell Biol. 218, 615-631. doi: 10.1083/jcb.201806153

Cullen, P. J., and Steinberg, F. (2018). To degrade or not to degrade: mechanisms and significance of endocytic recycling. Nat. Rev. Mol. Cell Biol. 19, 679-696. doi: 10.1038/s41580-018-0053-7

Daumke, O., Lundmark, R., Vallis, Y., Martens, S., Butler, P. J., and McMahon, H. T. (2007). Architectural and mechanistic insights into an EHD ATPase involved in membrane remodelling. Nature 449, 923-927. doi: 10.1038/nature06173

de Bot, S. T., Vermeer, S., Buijsman, W., Heister, A., Voorendt, M., Verrips, A., et al. (2013). Pure adult-onset spastic paraplegia caused by a novel mutation in the KIAA0196 (SPG8) gene. J. Neurol. 260, 1765-1769. doi: 10.1007/s00415013-6870-x

Derby, M. C., Lieu, Z. Z., Brown, D., Stow, J. L., Goud, B., and Gleeson, P. A. (2007). The trans-Golgi network golgin, GCC185, is required for endosometo-Golgi transport and maintenance of Golgi structure. Traffic 8, 758-773. doi: 10.1111/j.1600-0854.2007.00563.x

Derivery, E., Sousa, C., Gautier, J. J., Lombard, B., Loew, D., and Gautreau, A. (2009). The Arp $2 / 3$ activator WASH controls the fission of endosomes through a large multiprotein complex. Dev. Cell 17, 712-723. doi: 10.1016/j.devcel.2009. 09.010

Dong, R., Saheki, Y., Swarup, S., Lucast, L., Harper, J. W., and De Camilli, P. (2016). Endosome-ER contacts control actin nucleation and retromer function through VAP-dependent regulation of PI4P. Cell 166, 408-423. doi: 10.1016/j.cell.2016. 06.037

Elliott, A. M., Simard, L. R., Coghlan, G., Chudley, A. E., Chodirker, B. N., Greenberg, C. R., et al. (2013). A novel mutation in KIAA0196: identification of a gene involved in Ritscher-Schinzel/3C syndrome in a First Nations cohort. J. Med. Genet. 50, 819-822. doi: 10.1136/jmedgenet-2013-101715

Elwell, C. A., Czudnochowski, N., von Dollen, J., Johnson, J. R., Nakagawa, R., Mirrashidi, K., et al. (2017). Chlamydia interfere with an interaction between the mannose-6-phosphate receptor and sorting nexins to counteract host restriction. eLife 6:e22709. doi: 10.7554/eLife.22709

Fjorback, A. W., Seaman, M., Gustafsen, C., Mehmedbasic, A., Gokool, S., Wu, C., et al. (2012). Retromer binds the FANSHY sorting motif in SorLA to regulate amyloid precursor protein sorting and processing. J. Neurosci. 32, 1467-1480. doi: 10.1523/JNEUROSCI.2272-11.2012

Follett, J., Norwood, S. J., Hamilton, N. A., Mohan, M., Kovtun, O., Tay, S., et al. (2014). The Vps35 D620N mutation linked to Parkinson's disease disrupts the cargo sorting function of retromer. Traffic 15, 230-244. doi: 10.1111/tra.12136

Freeman, C. L., Hesketh, G., and Seaman, M. N. (2014). RME-8 coordinates the activity of the WASH complex with the function of the retromer SNX dimer to control endosomal tubulation. J. Cell Sci. 127(Pt 9), 2053-2070. doi: 10.1242/ jcs. 144659

Friedman, J. R., Lackner, L. L., West, M., DiBenedetto, J. R., Nunnari, J., and Voeltz, G. K. (2011). ER tubules mark sites of mitochondrial division. Science 334, 358-362. doi: 10.1126/science. 1207385

Gallon, M., Clairfeuille, T., Steinberg, F., Mas, C., Ghai, R., Sessions, R. B., et al. (2014). A unique PDZ domain and arrestin-like fold interaction reveals mechanistic details of endocytic recycling by SNX27-retromer. Proc. Natl. Acad. Sci. U.S.A. 111, E3604-E3613. doi: 10.1073/pnas.1410552111

Ghosh, R. N., Mallet, W. G., Soe, T. T., McGraw, T. E., and Maxfield, F. R. (1998). An endocytosed TGN38 chimeric protein is delivered to the TGN after trafficking through the endocytic recycling compartment in CHO cells. J. Cell Biol. 142, 923-936. doi: 10.1083/jcb.142.4.923

Gillingham, A. K., and Munro, S. (2016). Finding the Golgi: golgin coiled-coil proteins show the way. Trends Cell Biol. 26, 399-408. doi: 10.1016/j.tcb.2016. 02.005

Gokool, S., Tattersall, D., and Seaman, M. N. (2007). EHD1 interacts with retromer to stabilize SNX1 tubules and facilitate endosome-to-Golgi retrieval. Traffic 8, 1873-1886. doi: 10.1111/j.1600-0854.2007.00652.x

Goldstein, J. L., and Brown, M. S. (2001). Molecular medicine. The cholesterol quartet. Science 292, 1310-1312. doi: 10.1126/science.1061815

Gomez, T. S., and Billadeau, D. D. (2009). A FAM21-containing WASH complex regulates retromer-dependent sorting. Dev. Cell 17, 699-711. doi: 10.1016/j. devcel.2009.09.009

Gomez, T. S., Gorman, J. A., de Narvajas, A. A., Koenig, A. O., and Billadeau, D. D. (2012). Trafficking defects in WASH-knockout fibroblasts originate from 
collapsed endosomal and lysosomal networks. Mol. Biol. Cell 23, 3215-3228. doi: 10.1091/mbc.E12-02-0101

Harbour, M. E., Breusegem, S. Y., Antrobus, R., Freeman, C., Reid, E., and Seaman, M. N. (2010). The cargo-selective retromer complex is a recruiting hub for protein complexes that regulate endosomal tubule dynamics. J. Cell Sci. $123(\mathrm{Pt}$ 21), 3703-3717. doi: 10.1242/jcs.071472

Harbour, M. E., Breusegem, S. Y., and Seaman, M. N. (2011). Recruitment of the endosomal WASH complex is mediated by the extended "tail" of Fam21 binding to the retromer protein VPS35. Biochem. J. 442, 209-220. doi: 10.1042/ BJ20111761

Harbour, M. E., Breusegem, S. Y., and Seaman, M. N. (2012). Recruitment of the endosomal WASH complex is mediated by the extended 'tail' of Fam 21 binding to the retromer protein Vps35. Biochem. J. 442, 209-220.

Harripaul, R., Vasli, N., Mikhailov, A., Rafiq, M. A., Mittal, K., Windpassinger, C., et al. (2018). Mapping autosomal recessive intellectual disability: combined microarray and exome sequencing identifies 26 novel candidate genes in 192 consanguineous families. Mol. Psychiatry 23, 973-984. doi: 10.1038/mp.2017.60

Harrison, M. S., Hung, C. S., Liu, T. T., Christiano, R., Walther, T. C., and Burd, C. G. (2014). A mechanism for retromer endosomal coat complex assembly with cargo. Proc. Natl. Acad. Sci. U.S.A. 111, 267-272. doi: 10.1073/pnas.131648 2111

Harterink, M., Port, F., Lorenowicz, M. J., McGough, I. J., Silhankova, M., Betist, M. C., et al. (2011). A SNX3-dependent retromer pathway mediates retrograde transport of the Wnt sorting receptor Wntless and is required for Wnt secretion. Nat. Cell Biol. 13, 914-923. doi: 10.1038/ncb2281

Hensiek, A., Kirker, S., and Reid, E. (2015). Diagnosis, investigation and management of hereditary spastic paraplegias in the era of next-generation sequencing. J. Neurol. 262, 1601-1612. doi: 10.1007/s00415-014-7598-y

Hernandez-Valladares, M., Kim, T., Kannan, B., Tung, A., Aguda, A. H., Larsson, M., et al. (2010). Structural characterization of a capping protein interaction motif defines a family of actin filament regulators. Nat. Struct. Mol. Biol. 17, 497-503. doi: 10.1038/nsmb.1792

Hirst, J., Borner, G. H., Antrobus, R., Peden, A. A., Hodson, N. A., Sahlender, D. A., et al. (2012). Distinct and overlapping roles for AP-1 and GGAs revealed by the "knocksideways" system. Curr. Biol. 22, 1711-1716. doi: 10.1016/j.cub.2012.07. 012

Hirst, J., Borner, G. H., Edgar, J., Hein, M. Y., Mann, M., Buchholz, F., et al. (2013). Interaction between AP-5 and the hereditary spastic paraplegia proteins SPG11 and SPG15. Mol. Biol. Cell 24, 2558-2569. doi: 10.1091/mbc.E13-03-0170

Hirst, J., Miller, S. E., Taylor, M. J., von Mollard, G. F., and Robinson, M. S. (2004). EpsinR is an adaptor for the SNARE protein Vtilb. Mol. Biol. Cell 15, 5593-5602. doi: 10.1091/mbc.e04-06-0468

Hoyer, M. J., Chitwood, P. J., Ebmeier, C. C., Striepen, J. F., Qi, R. Z., Old, W. M., et al. (2018). A novel class of ER membrane proteins regulates ER-associated endosome fission. Cell 175, 254-265.e14. doi: 10.1016/j.cell.2018.08.030

Huang, W., Liu, Z., Yang, F., Zhou, H., Yong, X., Yang, X., et al. (2019). Structural and functional studies of TBC1D23 C-terminal domain provide a link between endosomal trafficking and PCH. Proc. Natl. Acad. Sci. U.S.A. 116, 22598-22608. doi: 10.1073/pnas.1909316116

Ivanova, E. L., Mau-Them, F. T., Riazuddin, S., Kahrizi, K., Laugel, V., Schaefer, E., et al. (2017). Homozygous truncating variants in TBC1D23 cause pontocerebellar hypoplasia and alter cortical development. Am. J. Hum. Genet. 101, 428-440. doi: 10.1016/j.ajhg.2017.07.010

Jia, D., Gomez, T. S., Billadeau, D. D., and Rosen, M. K. (2012). Multiple repeat elements within the FAM21 tail link the WASH actin regulatory complex to the retromer. Mol. Biol. Cell 23, 2352-2361. doi: 10.1091/mbc.E11-12-1059

Jia, D., Gomez, T. S., Metlagel, Z., Umetani, J., Otwinowski, Z., Rosen, M. K., et al. (2010). WASH and WAVE actin regulators of the Wiskott-Aldrich syndrome protein (WASP) family are controlled by analogous structurally related complexes. Proc. Natl. Acad. Sci. U.S.A. 107, 10442-10447. doi: 10.1073/ pnas.0913293107

Jia, D., Zhang, J. S., Li, F., Wang, J., Deng, Z., White, M. A., et al. (2016). Structural and mechanistic insights into regulation of the retromer coat by TBC1d5. Nat. Commun. 7:13305. doi: 10.1038/ncomms13305

Jimenez-Orgaz, A., Kvainickas, A., Nagele, H., Denner, J., Eimer, S., Dengjel, J., et al. (2018). Control of RAB7 activity and localization through the retromerTBC1D5 complex enables RAB7-dependent mitophagy. EMBO J. 37, 235-254. doi: $10.15252 /$ embj. 201797128
Kim, H. G., Ahn, J. W., Kurth, I., Ullmann, R., Kim, H. T., Kulharya, A., et al. (2010). WDR11, a WD protein that interacts with transcription factor EMX1, is mutated in idiopathic hypogonadotropic hypogonadism and Kallmann syndrome. Am. J. Hum. Genet. 87, 465-479. doi: 10.1016/j.ajhg.2010. 08.018

Kim, Y. J., Osborn, D. P., Lee, J. Y., Araki, M., Araki, K., Mohun, T., et al. (2018). WDR11-mediated Hedgehog signalling defects underlie a new ciliopathy related to Kallmann syndrome. EMBO Rep. 19, 269-289. doi: 10.15252/embr. 201744632

Kvainickas, A., Jimenez-Orgaz, A., Nagele, H., Hu, Z., Dengjel, J., and Steinberg, F. (2017a). Cargo-selective SNX-BAR proteins mediate retromer trimer independent retrograde transport. J. Cell Biol. 216, 3677-3693. doi: 10.1083/jcb. 201702137

Kvainickas, A., Nagele, H., Qi, W., Dokladal, L., Jimenez-Orgaz, A., Stehl, L., et al. (2019). Retromer and TBC1D5 maintain late endosomal RAB7 domains to enable amino acid-induced mTORC1 signaling. J. Cell Biol. 218, 3019-3038. doi: $10.1083 /$ jcb.201812110

Kvainickas, A., Orgaz, A. J., Nagele, H., Diedrich, B., Heesom, K. J., Dengjel, J. et al. (2017b). Retromer- and WASH-dependent sorting of nutrient transporters requires a multivalent interaction network with ANKRD50. J. Cell Sci. 130, 382-395. doi: $10.1242 /$ jcs. 196758

Liu, J. J. (2016). Retromer-mediated protein sorting and vesicular trafficking. J. Genet. Genomics 43, 165-177. doi: 10.1016/j.jgg.2016.02.006

Lu, L., and Hong, W. (2014). From endosomes to the trans-Golgi network. Semin. Cell Dev. Biol. 31, 30-39. doi: 10.1016/j.semcdb.2014.04.024

Lucas, M., Gershlick, D. C., Vidaurrazaga, A., Rojas, A. L., Bonifacino, J. S., and Hierro, A. (2016). Structural mechanism for cargo recognition by the retromer complex. Cell 167, 1623-1635.e14. doi: 10.1016/j.cell.2016.10.056

Lucas, M., and Hierro, A. (2017). Retromer. Curr. Biol. 27, R687-R689. doi: 10 1016/j.cub.2017.05.072

MacDonald, E., Brown, L., Selvais, A., Liu, H., Waring, T., Newman, D., et al. (2018). HRS-WASH axis governs actin-mediated endosomal recycling and cell invasion. J. Cell Biol. 217, 2549-2564. doi: 10.1083/jcb.201710051

Mallet, W. G., and Maxfield, F. R. (1999). Chimeric forms of furin and TGN38 are transported with the plasma membrane in the trans-Golgi network via distinct endosomal pathways. J. Cell Biol. 146, 345-359.

Mannan, A. U., Krawen, P., Sauter, S. M., Boehm, J., Chronowska, A., Paulus, W., et al. (2006). ZFYVE27 (SPG33), a novel spastin-binding protein, is mutated in hereditary spastic paraplegia. Am. J. Hum. Genet. 79, 351-357. doi: 10.1086/ 504927

Marin-Valencia, I., Gerondopoulos, A., Zaki, M. S., Ben-Omran, T., Almureikhi, M., Demir, E., et al. (2017). Homozygous mutations in TBC1D23 lead to a non-degenerative form of pontocerebellar hypoplasia. Am. J. Hum. Genet. 101, 441-450. doi: 10.1016/j.ajhg.2017.07.015

McGough, I. J., Steinberg, F., Jia, D., Barbuti, P. A., McMillan, K. J., Heesom, K. J., et al. (2014). Retromer binding to FAM21 and the WASH complex is perturbed by the Parkinson disease-linked VPS35(D620N) mutation. Curr. Biol. 24, 1670-1676. doi: 10.1016/j.cub.2014.06.024

McKenzie, J. E., Raisley, B., Zhou, X., Naslavsky, N., Taguchi, T., Caplan, S. et al. (2012). Retromer guides STxB and CD8-M6PR from early to recycling endosomes, EHD1 guides STxB from recycling endosome to Golgi. Traffic 13, 1140-1159. doi: 10.1111/j.1600-0854.2012.01374.x

McMillan, K. J., Korswagen, H. C., and Cullen, P. J. (2017). The emerging role of retromer in neuroprotection. Curr. Opin. Cell Biol. 47, 72-82. doi: 10.1016/j. ceb.2017.02.004

McNally, K. E., Faulkner, R., Steinberg, F., Gallon, M., Ghai, R., Pim, D., et al. (2017). Retriever is a multiprotein complex for retromer-independent endosomal cargo recycling. Nat. Cell Biol. 19, 1214-1225. doi: 10.1038/ncb3610

Meyer, C., Zizioli, D., Lausmann, S., Eskelinen, E. L., Hamann, J., Saftig, P., et al. (2000). mulA-adaptin-deficient mice: lethality, loss of AP-1 binding and rerouting of mannose 6-phosphate receptors. EMBO J. 19, 2193-2203. doi: 10.1093/emboj/19.10.2193

Miller, P. M., Folkmann, A. W., Maia, A. R., Efimova, N., Efimov, A., and Kaverina, I. (2009). Golgi-derived CLASP-dependent microtubules control Golgi organization and polarized trafficking in motile cells. Nat. Cell Biol. 11, 1069-1080. doi: 10.1038/ncb1920

Miura, E., Hasegawa, T., Konno, M., Suzuki, M., Sugeno, N., Fujikake, N., et al. (2014). VPS35 dysfunction impairs lysosomal degradation of alpha-synuclein 
and exacerbates neurotoxicity in a Drosophila model of Parkinson's disease. Neurobiol. Dis. 71, 1-13. doi: 10.1016/j.nbd.2014.07.014

Monfregola, J., Napolitano, G., D’Urso, M., Lappalainen, P., and Ursini, M. V. (2010). Functional characterization of Wiskott-Aldrich syndrome protein and scar homolog (WASH), a bi-modular nucleation-promoting factor able to interact with biogenesis of lysosome-related organelle subunit 2 (BLOS2) and gamma-tubulin. J. Biol. Chem. 285, 16951-16957. doi: 10.1074/jbc.M109. 078501

Mukhopadhyay, A., Pan, X., Lambright, D. G., and Tissenbaum, H. A. (2007). An endocytic pathway as a target of tubby for regulation of fat storage. EMBO Rep. 8, 931-938. doi: 10.1038/sj.embor.7401055

Mukhopadhyay, S., and Linstedt, A. D. (2012). Manganese blocks intracellular trafficking of Shiga toxin and protects against Shiga toxicosis. Science 335, 332-335. doi: 10.1126/science. 1215930

Munro, S. (2011). The golgin coiled-coil proteins of the Golgi apparatus. Cold Spring Harb. Perspect. Biol. 3:a005256. doi: 10.1101/cshperspect.a005256

Namavar, Y., Barth, P. G., Poll-The, B. T., and Baas, F. (2011). Classification, diagnosis and potential mechanisms in pontocerebellar hypoplasia. Orphanet. J. Rare Dis. 6:50. doi: 10.1186/1750-1172-6-50

Navarro Negredo, P., Edgar, J. R., Manna, P. T., Antrobus, R., and Robinson, M. S. (2018). The WDR11 complex facilitates the tethering of AP-1-derived vesicles. Nat. Commun. 9:596. doi: 10.1038/s41467-018-02919-4

Nielsen, M. S., Madsen, P., Christensen, E. I., Nykjaer, A., Gliemann, J., Kasper, D., et al. (2001). The sortilin cytoplasmic tail conveys Golgi-endosome transport and binds the VHS domain of the GGA2 sorting protein. EMBO J. 20, 2180 2190. doi: 10.1093/emboj/20.9.2180

Nothwehr, S. F., Ha, S. A., and Bruinsma, P. (2000). Sorting of yeast membrane proteins into an endosome-to-Golgi pathway involves direct interaction of their cytosolic domains with Vps35p. J. Cell Biol. 151, 297-310. doi: 10.1083/jcb.151. 2.297

Pan, X., Eathiraj, S., Munson, M., and Lambright, D. G. (2006). TBC-domain GAPs for Rab GTPases accelerate GTP hydrolysis by a dual-finger mechanism. Nature 442, 303-306. doi: 10.1038/nature04847

Park, S. Y., and Guo, X. (2014). Adaptor protein complexes and intracellular transport. Biosci. Rep. 34:e00123. doi: 10.1042/BSR20140069

Paul, B., Kim, H. S., Kerr, M. C., Huston, W. M., Teasdale, R. D., and Collins, B. M. (2017). Structural basis for the hijacking of endosomal sorting nexin proteins by Chlamydia trachomatis. eLife 6:e22311. doi: 10.7554/eLife.22311

Perez-Victoria, F. J., Mardones, G. A., and Bonifacino, J. S. (2008). Requirement of the human GARP complex for mannose 6-phosphate-receptor-dependent sorting of cathepsin D to lysosomes. Mol. Biol. Cell 19, 2350-2362. doi: 10.1091/ mbc.E07-11-1189

Phillips-Krawczak, C. A., Singla, A., Starokadomskyy, P., Deng, Z., Osborne, D. G., Li, H., et al. (2015). COMMD1 is linked to the WASH complex and regulates endosomal trafficking of the copper transporter ATP7A. Mol. Biol. Cell 26, 91-103. doi: 10.1091/mbc.E14-06-1073

Piotrowski, J. T., Gomez, T. S., Schoon, R. A., Mangalam, A. K., and Billadeau, D. D. (2013). WASH knockout T cells demonstrate defective receptor trafficking, proliferation, and effector function. Mol. Cell. Biol. 33, 958-973. doi: 10.1128/ MCB.01288-12

Puthenveedu, M. A., Lauffer, B., Temkin, P., Vistein, R., Carlton, P., Thorn, K., et al. (2010). Sequence-dependent sorting of recycling proteins by actin-stabilized endosomal microdomains. Cell 143, 761-773. doi: 10.1016/j.cell.2010.10.003

Raiborg, C., Wenzel, E. M., and Stenmark, H. (2015). ER-endosome contact sites: molecular compositions and functions. EMBO J. 34, 1848-1858. doi: 10.15252/ embj.201591481

Rapoport, I., Chen, Y. C., Cupers, P., Shoelson, S. E., and Kirchhausen, T. (1998). Dileucine-based sorting signals bind to the beta chain of AP-1 at a site distinct and regulated differently from the tyrosine-based motif-binding site. EMBO J. 17, 2148-2155. doi: 10.1093/emboj/17.8.2148

Robinson, M. S., Sahlender, D. A., and Foster, S. D. (2010). Rapid inactivation of proteins by rapamycin-induced rerouting to mitochondria. Dev. Cell 18, 324-331. doi: 10.1016/j.devcel.2009.12.015

Roll-Mecak, A., and Vale, R. D. (2008). Structural basis of microtubule severing by the hereditary spastic paraplegia protein spastin. Nature 451, 363-367. doi: 10.1038 /nature 06482

Ropers, F., Derivery, E., Hu, H., Garshasbi, M., Karbasiyan, M., Herold, M., et al. (2011). Identification of a novel candidate gene for non-syndromic autosomal recessive intellectual disability: the WASH complex member SWIP. Hum. Mol. Genet. 20, 2585-2590. doi: 10.1093/hmg/ddr158

Rowland, A. A., Chitwood, P. J., Phillips, M. J., and Voeltz, G. K. (2014). ER contact sites define the position and timing of endosome fission. Cell 159, 1027-1041. doi: 10.1016/j.cell.2014.10.023

Rudnik-Schoneborn, S., Barth, P. G., and Zerres, K. (2014). Pontocerebellar hypoplasia. Am. J. Med. Genet. C Semin. Med. Genet. 166C, 173-183. doi: 10.1002/ajmg.c.31403

Ryder, P. V., Vistein, R., Gokhale, A., Seaman, M. N., Puthenveedu, M. A., and Faundez, V. (2013). The WASH complex, an endosomal Arp2/3 activator, interacts with the Hermansky-Pudlak syndrome complex BLOC-1 and its cargo phosphatidylinositol-4-kinase type IIalpha. Mol. Biol. Cell 24, 2269-2284. doi: 10.1091/mbc.E13-02-0088

Saimani, U., and Kim, K. (2017). Traffic from the endosome towards trans-Golgi network. Eur. J. Cell Biol. 96, 198-205. doi: 10.1016/j.ejcb.2017.02.005

Saint-Pol, A., Yélamos, B., Amessou, M., Mills, I. G., Dugast, M., Tenza, D., et al. (2004). Clathrin adaptor epsinR is required for retrograde sorting on early endosomal membranes. Dev. Cell 6, 525-538. doi: 10.1016/s1534-5807(04) 00100-5

Sandvig, K., and van Deurs, B. (2002). Transport of protein toxins into cells: pathways used by ricin, cholera toxin and Shiga toxin. FEBS Lett. 529, 49-53. doi: 10.1016/s0014-5793(02)03182-4

Schweizer, A., Stahl, P. D., and Rohrer, J. (2000). A di-aromatic motif in the cytosolic tail of the mannose receptor mediates endosomal sorting. J. Biol. Chem. 275, 29694-29700. doi: 10.1074/jbc.m000571200

Seaman, M. N. (2004). Cargo-selective endosomal sorting for retrieval to the Golgi requires retromer. J. Cell Biol. 165, 111-122. doi: 10.1083/jcb.200312034

Seaman, M. N. (2007). Identification of a novel conserved sorting motif required for retromer-mediated endosome-to-TGN retrieval. J. Cell Sci. 120(Pt 14), 2378-2389. doi: 10.1242/jcs.009654

Seaman, M. N. (2012). The retromer complex - endosomal protein recycling and beyond. J. Cell Sci. 125(Pt 20), 4693-4702. doi: 10.1242/jcs.103440

Seaman, M. N., Gautreau, A., and Billadeau, D. D. (2013). Retromer-mediated endosomal protein sorting: all WASHed up! Trends Cell Biol. 23, 522-528. doi: $10.1016 /$ j.tcb.2013.04.010

Seaman, M. N., Harbour, M. E., Tattersall, D., Read, E., and Bright, N. (2009). Membrane recruitment of the cargo-selective retromer subcomplex is catalysed by the small GTPase Rab7 and inhibited by the Rab-GAP TBC1D5. J. Cell Sci. 122(Pt 14), 2371-2382. doi: 10.1242/jcs.048686

Seaman, M. N., McCaffery, J. M., and Emr, S. D. (1998). A membrane coat complex essential for endosome-to-Golgi retrograde transport in yeast. J. Cell Biol. 142, 665-681. doi: 10.1083/jcb.142.3.665

Seaman, M. N. J. (2018). Retromer and the cation-independent mannose 6phosphate receptor-Time for a trial separation? Traffic 19, 150-152. doi: 10. $1111 /$ tra. 12542

Shi, M., Chen, B., Mahajan, D., Boh, B. K., Zhou, Y., Dutta, B., et al. (2018). Amino acids stimulate the endosome-to-Golgi trafficking through Ragulator and small GTPase Arl5. Nat. Commun. 9:4987. doi: 10.1038/s41467-018-07444-y

Shibata, Y., Voss, C., Rist, J. M., Hu, J., Rapoport, T. A., Prinz, W. A., et al. (2008). The reticulon and DP1/Yoplp proteins form immobile oligomers in the tubular endoplasmic reticulum. J. Biol. Chem. 283, 18892-18904. doi: 10.1074/ jbc.M800986200

Shin, J. J. H., Gillingham, A. K., Begum, F., Chadwick, J., and Munro, S. (2017). TBC1D23 is a bridging factor for endosomal vesicle capture by golgins at the trans-Golgi. Nat. Cell Biol. 19, 1424-1432. doi: 10.1038/ncb3627

Simonetti, B., Danson, C. M., Heesom, K. J., and Cullen, P. J. (2017). Sequencedependent cargo recognition by SNX-BARs mediates retromer-independent transport of CI-MPR. J. Cell Biol. 216, 3695-3712. doi: 10.1083/jcb.201703015

Simonetti, B., Paul, B., Chaudhari, K., Weeratunga, S., Steinberg, F., Gorla, M., et al. (2019). Molecular identification of a BAR domain-containing coat complex for endosomal recycling of transmembrane proteins. Nat. Cell Biol. 21, 1219-1233. doi: 10.1038/s41556-019-0393-3

Singla, A., Fedoseienko, A., Giridharan, S. S. P., Overlee, B. L., Lopez, A., Jia, D., et al. (2019). Endosomal PI(3)P regulation by the COMMD/CCDC22/CCDC93 (CCC) complex controls membrane protein recycling. Nat. Commun. 10:4271. doi: 10.1038/s41467-019-12221-6

Sleat, D. E., Wiseman, J. A., El-Banna, M., Price, S. M., Verot, L., Shen, M. M., et al. (2004). Genetic evidence for nonredundant functional cooperativity between 
NPC1 and NPC2 in lipid transport. Proc. Natl. Acad. Sci. U.S.A. 101, 5886-5891. doi: 10.1073/pnas.0308456101

Steinberg, F., Gallon, M., Winfield, M., Thomas, E. C., Bell, A. J., Heesom, K. J., et al. (2013). A global analysis of SNX27-retromer assembly and cargo specificity reveals a function in glucose and metal ion transport. Nat. Cell Biol. 15, 461-471. doi: $10.1038 /$ ncb2721

Sun, Q., Yong, X., Sun, X., Yang, F., Dai, Z., Gong, Y., et al. (2017). Structural and functional insights into sorting nexin 5/6 interaction with bacterial effector IncE. Signal Transduct. Target. Ther. 2:17030. doi: 10.1038/sigtrans.2017.30

Suzuki, S. W., Chuang, Y. S., Li, M., Seaman, M. N. J., and Emr, S. D. (2019). A bipartite sorting signal ensures specificity of retromer complex in membrane protein recycling. J. Cell Biol. 218, 2876-2886. doi: 10.1083/jcb.201901019

Takeda, S., Minakata, S., Koike, R., Kawahata, I., Narita, A., Kitazawa, M., et al. (2010). Two distinct mechanisms for actin capping protein regulation-steric and allosteric inhibition. PLoS Biol. 8:e1000416. doi: 10.1371/journal.pbio. 1000416

Teasdale, R. D., and Collins, B. M. (2012). Insights into the PX (phox-homology) domain and SNX (sorting nexin) protein families: structures, functions and roles in disease. Biochem. J. 441, 39-59. doi: 10.1042/BJ20111226

Temkin, P., Lauffer, B., Jager, S., Cimermancic, P., Krogan, N. J., and von Zastrow, M. (2011). SNX27 mediates retromer tubule entry and endosome-to-plasma membrane trafficking of signalling receptors. Nat. Cell Biol. 13, 715-721. doi: $10.1038 /$ ncb2252

Ungar, D., Oka, T., Krieger, M., and Hughson, F. M. (2006). Retrograde transport on the COG railway. Trends Cell Biol. 16, 113-120. doi: 10.1016/j.tcb.2005.12. 004

Valdmanis, P. N., Meijer, I. A., Reynolds, A., Lei, A., MacLeod, P., Schlesinger, D., et al. (2007). Mutations in the KIAA0196 gene at the SPG8 locus cause hereditary spastic paraplegia. Am. J. Hum. Genet. 80, 152-161. doi: 10.1086/ 510782

Vardarajan, B. N., Bruesegem, S. Y., Harbour, M. E., Inzelberg, R., Friedland, R., St George-Hyslop, P., et al. (2012). Identification of Alzheimer diseaseassociated variants in genes that regulate retromer function. Neurobiol. Aging 33, 2231.e15-2231.e30. doi: 10.1016/j.neurobiolaging.2012.04.020

Varlamov, O., and Fricker, L. D. (1998). Intracellular trafficking of metallocarboxypeptidase D in AtT-20 cells: localization to the trans-Golgi network and recycling from the cell surface. J. Cell Sci. 111(Pt 7), 877-885.

Verboon, J. M., Decker, J. R., Nakamura, M., and Parkhurst, S. M. (2018). Wash exhibits context-dependent phenotypes and, along with the WASH regulatory complex, regulates Drosophila oogenesis. J. Cell Sci. 131:jcs211573. doi: 10. $1242 /$ jcs. 211573

Vilarino-Guell, C., Wider, C., Ross, O. A., Dachsel, J. C., Kachergus, J. M., Lincoln, S. J., et al. (2011). VPS35 mutations in Parkinson disease. Am. J. Hum. Genet. 89, 162-167. doi: 10.1016/j.ajhg.2011.06.001

Wan, L., Molloy, S. S., Thomas, L., Liu, G., Xiang, Y., Rybak, S. L., et al. (1998). PACS-1 defines a novel gene family of cytosolic sorting proteins required for trans-Golgi network localization. Cell 94, 205-216. doi: 10.1016/s00928674(00)81420-8

Wang, J., Fedoseienko, A., Chen, B., Burstein, E., Jia, D., and Billadeau, D. D. (2018). Endosomal receptor trafficking: retromer and beyond. Traffic 19, 578590. doi: 10.1111/tra.12574

Wassmer, T., Attar, N., Bujny, M. V., Oakley, J., Traer, C. J., and Cullen, P. J. (2007). A loss-of-function screen reveals SNX5 and SNX6 as potential components of the mammalian retromer. J. Cell Sci. 120(Pt 1), 45-54. doi: 10.1242/ jcs. 03302
Whyte, J. R., and Munro, S. (2002). Vesicle tethering complexes in membrane traffic. J. Cell Sci. 115(Pt 13), 2627-2637.

Willnow, T. E., and Andersen, O. M. (2013). Sorting receptor SORLA-a trafficking path to avoid Alzheimer disease. J. Cell Sci. 126(Pt 13), 2751-2760. doi: 10.1242/ jcs. 125393

Witkos, T. M., and Lowe, M. (2015). The Golgin family of coiled-coil tethering proteins. Front. Cell. Dev. Biol. 3:86. doi: 10.3389/fcell.2015.00086

Wong, M., and Munro, S. (2014). Membrane trafficking. The specificity of vesicle traffic to the Golgi is encoded in the golgin coiled-coil proteins. Science 346:1256898. doi: 10.1126/science. 1256898

Wu, H., Carvalho, P., and Voeltz, G. K. (2018). Here, there, and everywhere: the importance of ER membrane contact sites. Science 361:eaan5835. doi: 10.1126/ science.aan5835

Xia, P., Wang, S., Du, Y., Zhao, Z., Shi, L., Sun, L., et al. (2013). WASH inhibits autophagy through suppression of Beclin 1 ubiquitination. EMBO J. 32, 26852696. doi: 10.1038/emboj.2013.189

Yu, I. M., and Hughson, F. M. (2010). Tethering factors as organizers of intracellular vesicular traffic. Annu. Rev. Cell Dev. Biol. 26, 137-156. doi: 10. 1146/annurev.cellbio.042308.113327

Zavodszky, E., Seaman, M. N., Moreau, K., Jimenez-Sanchez, M., Breusegem, S. Y., Harbour, M. E., et al. (2014). Mutation in VPS35 associated with Parkinson's disease impairs WASH complex association and inhibits autophagy. Nat. Commun. 5:3828. doi: 10.1038/ncomms4828

Zech, T., Calaminus, S. D., Caswell, P., Spence, H. J., Carnell, M., Insall, R. H., et al. (2011). The Arp2/3 activator WASH regulates alpha5betal-integrin-mediated invasive migration. J. Cell Sci. 124(Pt 22), 3753-3759. doi: 10.1242/jcs.080986

Zeevaert, R., Foulquier, F., Jaeken, J., and Matthijs, G. (2008). Deficiencies in subunits of the conserved oligomeric Golgi (COG) complex define a novel group of congenital disorders of glycosylation. Mol. Genet. Metab. 93, 15-21. doi: 10.1016/j.ymgme.2007.08.118

Zhang, J., Reiling, C., Reinecke, J. B., Prislan, I., Marky, L. A., Sorgen, P. L., et al. (2012). Rabankyrin-5 interacts with EHD1 and Vps26 to regulate endocytic trafficking and retromer function. Traffic 13, 745-757. doi: 10.1111/j.16000854.2012.01334.x

Zhang, P., Wu, Y., Belenkaya, T. Y., and Lin, X. (2011). SNX3 controls Wingless/Wnt secretion through regulating retromer-dependent recycling of Wntless. Cell Res. 21, 1677-1690. doi: 10.1038/cr.2011.167

Zimprich, A., Benet-Pages, A., Struhal, W., Graf, E., Eck, S. H., Offman, M. N. A., et al. (2011). A mutation in VPS35, encoding a subunit of the retromer complex, causes late-onset Parkinson disease. Am. J. Hum. Genet. 89, 168-175. doi: 10.1016/j.ajhg.2011.06.008

Zolov, S. N., and Lupashin, V. V. (2005). Cog3p depletion blocks vesicle-mediated Golgi retrograde trafficking in HeLa cells. J. Cell Biol. 168, 747-759. doi: $10.1083 /$ jcb. 200412003

Conflict of Interest: The authors declare that the research was conducted in the absence of any commercial or financial relationships that could be construed as a potential conflict of interest.

Copyright (c) $2020 \mathrm{Tu}$, Zhao, Billadeau and Jia. This is an open-access article distributed under the terms of the Creative Commons Attribution License (CC BY). The use, distribution or reproduction in other forums is permitted, provided the original author(s) and the copyright owner(s) are credited and that the original publication in this journal is cited, in accordance with accepted academic practice. No use, distribution or reproduction is permitted which does not comply with these terms. 